Article

\title{
Things Are Not What They Seem: The Transcendentalism of Appearances in the Refutation of Reductive Naturalism
}

\section{James Trafford}

\begin{abstract}
In this paper, I will re-examine the refutation of reductive naturalism by the anti-reductionist and the phenomenologist. I want first to outline a possible way of consistently polarising the field by showing that the anti-reductionist and phenomenologist adhere, at least to some degree, to what I will call the 'principle of appearing qua appearing.' The exemplar of reductive naturalism that I will go on to use is the work of Thomas Metzinger, which has come under serious criticism from phenomenologists. While this criticism has often assumed that Metzinger conflates phenomenology with introspection, I think that this is simply a terminological issue that will be sidestepped in order to look at the deeper problems that Metzinger's work poses to the refutation of reductive naturalism. I go on to argue that this refutation relies upon the transcendentalism of appearances, and can be considered to be question begging. I will then consider three possible responses to my argument.
\end{abstract}

Key words: Metzinger, reductive naturalism, transcendentalism, phenomenolgy

\section{The Principle of Appearing Qua Appearing}

$\mathrm{W}$

ith regard to consciousness, I would like to polarise the field by promoting a unifying principle for those anti-reductive philosophers who assume both that consciousness exists, and, as Ned Block puts it; that "[o]ur fundamental access to consciousness derives from our acquaintance with it." David Chalmers, for example states: "I have assumed that consciousness exists [...] although I can no more 'prove' it than I can prove that I am conscious." 2 Whilst phenomenology is most concerned with how things appear to us, I will also suppose that this is an unproblematic

${ }^{1}$ Ned Block, "Begging the Question against Phenomenal Consciousness," in Behaviour and Brain Sciences, 15:2 (1992), 205.

2 David Chalmers, "Reply to Mulhauser's Review of "The Conscious Mind," in Psyche, 2:35 (November 1996).

(c) 2011 James Trafford

http://www.kritike.org/journal/issue 10/trafford december2011.pdf ISSN 1908-7330 
account of Husserlian phenomenology: for example, Husserl states that "[T]he objects of which we are 'conscious,' are not simply in consciousness as in a box [...] they are first constituted as being, what they are for us, and as what they count as for us." 3 Such philosophers have intuition on their side, claiming that the burden of explanation would most definitely rest with philosophers such as Daniel Dennett and Metzinger to establish a significant and substantial argument to the contrary. ${ }^{4}$ Chalmers lucidly delineates the ramifications of this position: Subjective experience is where our attempt to understand the world begins, and as such, is given to us as a brute fact, whose existence is not open to question: "If it were not for the fact that first-person experience was a brute fact presented to us, there would seem to be no reason to predict its existence." 5

Now, I want to assert that there is a second and sometimes implicit premise that the anti-reductionist and phenomenologist share: Conscious experience should be understood to be the domain of appearances as such. John Searle articulates this point: "Consciousness consists in the appearances themselves. Where appearance is concerned we cannot make the appearancereality distinction because the appearance is the reality." 6 I want to call this the 'principle of appearing qua appearing,' or AqA.7 Even if we accept Block's distinction of access consciousness (AC) and phenomenal consciousness (PC), (or Chalmers' similar distinction between psychological and phenomenal consciousness), the principle of AqA holds for phenomenal consciousness, since, for Block; "P-consciousness, as such, is not consciousness of."

Following the above two premises, we can suggest that two conclusions follow, one positive and one negative. First, consciousness should

\footnotetext{
${ }^{3}$ Edmund Husserl, Logical Investigations I (London: Routledge, 2001), 275.

${ }^{4}$ David Chalmers, "Moving Forward on the Problem of Consciousness," in The Journal of Consciousness Studies, 4:1 (1997), 9.

5 David Chalmers, "Consciousness and Cognition," (1990) http://consc.net/ papers/c-and-c.html.

${ }^{6}$ John Searle, The Rediscovery of the Mind (Cambridge, Mass: MIT Press, 1992), 121. Dennett's verificationist account has been touted as also refusing the appearance / reality distinction (e.g. Glenn Carruthers \& Elizabeth Schier, "Our Intuitions about Consciousness are Inconsistent," Paper presented at the Australasian Association for Philosophy Conference, Melbourne, Australia. July 2008). However, it may be that such a view equivocates on the notion of consciousness in Dennett's early work, since he quite clearly states: "There seems to be phenomenology [...] But it does not follow from this undeniable, universally attested fact that there really is phenomenology." Daniel Dennett, Consciousness Explained, (Boston: Little Brown, 1991), 336. Dennett refuses the transcendentalism of appearances, but his refusal of an appearance / reality distinction for subjective access seems most likely to be a result of his intent to disavow the Cartesian theatre in this manner.

7 The term 'appearing qua appearing' has been used previously by phenomenologists such as Jan Patocka, An Introduction to Husserl's Phenomenology, trans. by Erazim Kohak (Chicago, IL: Open Court, 1996).

${ }^{8}$ Ned Block, "On a Confusion about a Concept of Consciousness," in Behaviour and Brain Sciences, 18: 2 (1995). However, Güzeldere and Aydede provide a fairly convincing argument against the legitimacy of Block's distinction of AC and PC. Cf. Guven Güzeldere and Murat Aydede, "On the Relation Between Phenomenal and Representational Properties," in Behavioural and Brain Sciences, 20:1 (1997).
} 
be ostensively defined, and taken to be an "irreducible aspect of reality," as Thomas Nagel put it, an explanandum that blocks the integration of the firstperson point of view into the third-person scientific viewpoint. This claim need not be metaphysical, it need simply to assert as Levine does: "[T] hat conscious experiences themselves, not merely our verbal judgments about them, are the primary data to which a theory must answer." 10

Second, that reductionism with regard to consciousness is selfrefuting, since it ignores that which it would presume to explain. Depending upon philosophical allegiance, this refutation takes different forms. For example, Searle argues that: scientific reduction attempts to reveal the reality behind appearances, however, in the case of consciousness, reality and appearance are inseparable - appearance is the reality - and thus, there can be no reduction. Let us also quickly follow Chalmers who argues that:

If someone says 'I can see that you have explained how DNA stores and transmits hereditary information [...] but you have not explained how it is a gene,' then they are making a conceptual mistake. All it means to be a gene is to be an entity that performs the relevant storage and transmission function. When someone says 'I can see that you have explained how information is discriminated, integrated, and reported, but you have not explained how it is experienced,' they are not making a conceptual mistake. This is a nontrivial further question. ${ }^{11}$

To reiterate the premises and conclusions of the above antireductionist argument:

1. Consciousness exists, and is given to the first-person in experience as a brute fact.

2. There can be no appearance / reality distinction as far as consciousness is concerned (AqA).

9 Thomas Nagel, "Conceiving the Impossible and the Mind-Body Problem," in Philosophy, 73: 285 (1998), 338.

${ }^{10}$ Joseph Levine, "Out of the closet: A qualophile confronts qualophobia," in Philosophical Topics, 22 (1994), 107-26. Levine assumes both that the distinction between the experiences themselves and our reports upon them is assured, and that we have a common-sense intuition regarding what this 'primary data' is supposed to be.

11 David Chalmers, "Facing up to the Problem of Consciousness," in The Journal of Consciousness Studies, 2:3 (1995), 203. Cf. Galen Strawson: "[F]or there to seem to be rich phenomenology or experience just is for there to be such phenomenology or experience." Galen Strawson, "Realistic Monism," in Alan Freeman ed., Consciousness and it's Place in Nature: Does Physicalism Entail Panpsychism? (Exeter: Imprint, 2006), 6n7. 
C1. Consciousness is an irreducible aspect of the world that resists objective description. ${ }^{12}$

C2. Reductive naturalism is self-refuting.

All of the above claims are central to phenomenological philosophy, and appear, for example, in Sonja Rinofner-Kreidl's critique of Metzinger. However, it is clear that these assertions are transcendental as far as phenomenologists are concerned. Consider Jan Patocka's statement: "I cannot go back to what appears to explain the appearing of appearing, since the understanding of appearing is presupposed in every thesis I might make about the appearing entity." 13 There is a transcendental assertion that precludes us from explaining the appearing of appearing, since this would induce a vicious circularity in our argumentation - it would necessitate us 'forgetting' the very conditions upon which we are able to make statements. ${ }^{14}$ By treating consciousness as one object amongst others, we would be engaging in a performative contradiction, since it is the very dimension of consciousness that gives us access to the world in the first place. ${ }^{15}$

This argument hinges on the principle of AqA - that appearances should be accounted for on their own terms. Consider Husserl's 'principle of principles':

[T] hat every originary presentive intuition is a legitimizing source of cognition, that everything originally $[\ldots]$ offered to us in intuition is to be accepted simply as what it is presented as being, but also only within the limits in which it is presented there. ${ }^{16}$

12 Cf. Sonja Rinofner-Kreidl's critique of Metzinger on this point, "The Limits of Representationalism," in The Journal of Consciousness Studies, 11:10-11 (October-November, 2004), 369.

13 Jan Patocka, Plato and Europe, trans. by Petr Lom (Stanford: Stanford University Press, 2002), 24.

${ }_{14}$ Cf. Husserl: "If certain riddles are, generally speaking, inherent in principle to natural science, then it is self-evident that the solution of these riddles according to premises and conclusions in principle transcends natural science. To expect from natural science itself the solution of any one of the problems inherent in it as such [...] or even merely to suppose that it could contribute to the solution of such a problem any premise whatsoever, is to be involved in a vicious circle." Edmund Husserl, "Philosophy as a Rigorous Science," in P. McCormick and F. Elliston eds., Husserl: Shorter Works (Notre Dame: University of Notre Dame Press, 1911/1981), 172.

15 It is worth noting that the structure of this argument is similar to that made against eliminative materialism as 'self-defeating.' Cf. Lynne Rudder-Baker, Saving Belief: A Critique of Physicalism (Princeton, NJ: Princeton University Press, 1987) and Paul Churchland, "Eliminative Materialism and the Propositional Attitudes," in The Journal of Philosophy, 78:2, (1981), 76-90 for a fairly convincing response.

16 Edmund Husserl, Ideas pertaining to a Pure Phenomenology and to a Phenomenological Philosophy, First Book, trans. by F. Kersten (Dordrecht: Kluwer Academic Publishers, 1982), 44. This is also the case for weaker claims such as: "Introspective conception affords one a transparent understanding of the nature of one's mode of consciousness." Philip Goff, "Appearance, Reality, and the Reality of Appearance," Paper given at Brains Persons and Society, 
Philip Goff makes a similar (though weaker) argument:

When you attend, say, to your feeling of toothache, you are conceiving of that feature of reality $[\ldots]$ in terms of what it is like to have it. But the nature of the feeling of toothache is exhausted by what it's like to have it. ${ }^{17}$

From AqA, consciousness just is the way things appear to us - the first-person phenomenological subject - so there is an epistemic asymmetry that is ineliminable for reductive naturalism. ${ }^{18} \mathrm{It}$ is my claim that by holding the principle of $\mathrm{AqA}$, the anti-reductionist is as much of a transcendentalist as the phenomenologist. Why? Because the principle is a transcendental assertion precluding further explanation: experience is an explanandum, not an explanans, or as Chalmers puts it: "Conscious Experience [...] forces itself upon us as an explanandum and cannot be eliminated so easily." 19 The refutation of reductive naturalism rests upon the transcendentalism of conscious appearances, so that reductionism regarding those appearances is rejected not just as empirically false, but as necessarily false, and incoherent. To substantiate this claim, let us turn to Metzinger's form of reductive naturalism.

\section{Metzinger's Achievement}

Metzinger's work can be taken as a response to such transcendentalism in three ways: a) he provides a sub-personal naturalistic account of consciousness; b) he provides an account of our 'seeming' to be genuine subjects of experience; c) he argues that, in spite of this 'seeming,' there are no subjects of experience in the world. ${ }^{20}$ If we are to refuse the principle of AqA, the second is most important: it explains why we experience ourselves in terms of first person subjectivity as an explanandum. It is incumbent upon reductive

Milan (2006). Similarly, I would suggest that claims such as 'experiences are immediately familiar to the subject of experience,' and 'we have a privileged way of knowing our own thoughts, feelings, and sensations,' would fall under the same category.

${ }^{17}$ Ibid.

18 Cf. Chalmers: "[O]ur grounds for belief in consciousness derive solely from our own experience of it." David Chalmers, The Conscious Mind (Cambridge, MA: MIT Press, 1996), 101.

19 Ibid., 109. As Teed Rockwell remarks, Chalmers' 'Hard Problem' is in fact impossible to answer in the form in which it is formulated, since Chalmers argues that we cannot explain consciousness in terms of structure and function, yet this is precisely what an explanation consists of. Thus, for example, Chalmers defines function as: "Any causal role in the production of behavior that a system might perform." David Chalmers, "Facing up to the Problem of Consciousness," 202. If this is the case, then, as Rockwell notes, surely the 'hard problem' is not a problem at all since it in principle cannot be solved. Teed Rockwell, "The Hard Problem is Dead, Long Live the Hard Problem," < http://www.cognitivequestions.org/hardproblem.html>, (1999).

20 This list is lifted almost wholesale from Lynne Rudder Baker's summary of Metzinger's work, Lynne Rudder-Baker, Saving Belief: A Critique of Physicalism. 
naturalism to present a theory of why consciousness and first person experience seem to be a 'brute fact.' In order to achieve this, Metzinger has to account for appearances as such by making the distinction between explanandum and explanans untenable.

Primarily, Metzinger argues that phenomenal experience should be understood in terms of a process of mental presentation; a physically realised process that relates a system, and internal state of that system, and a partition of the world. This process generates a phenomenal representatum, or a presentatum (the vehicle of presentation), the content of which signals a presentandum for the system. Refusing to separate vehicle and content in this way, Metzinger uses this process to outline his understanding of phenomenal self-representation as the process by which the system as a whole generates the content of a selfrepresentational state. In this way, the system as a whole activates a self-model: a self-representatum that is a time-slice of the ongoing, physically realized process of representation.

In order for this self-model or system-model to become a phenomenal self - to move from representational self-modelling to the consciously experienced phenomenal property of selfhood - there is a transparency constraint. Metzinger understands certain properties of experience to be phenomenologically transparent. In contrast to the conception of phenomenal transparency proposed by G.E. Moore, and more recently, Sydney Shoemaker and Michael Tye, Metzinger defines transparency as follows: "For every phenomenal state, the degree of phenomenal transparency is inversely proportional to the introspective degree of attentional availability of earlier processing stages." 21 Transparency is the property of mental representations that gives rise to a phenomenal model of reality. It is this 'reality-model' that is experienced firsthand as pre-reflectively and immediately given to the self in the experience of presence within a world. Nevertheless, transparency results from an architectonic feature of the information processing that allows for the transparent activation of this mental model, since, for example, the earlier processing stages that unify conscious content are systematically deleted from the experience of the unified global model of the world. A phenomenal representatum or, as Metzinger puts it, a presentatum is one that cannot be recognized as such by the system activating it: consequently, we experience ourselves as living in the world right now.

In this respect, the relation between the presentatum and presentandum is essentially asymmetric since the earlier processing stages of representation are systematically occluded from the presentational content: phenomenal experience is a presentatum that emerges precisely as a result of the occlusion of the presentandum (the vehicle of presentation). The phenomenal experience of the self is also a form of mental content that is brought about specifically because of the deletion of earlier representational processes. So, what Metzinger calls the 'Phenomenal Self-Model' (PSM), is brought about by a

21 Thomas Metzinger, "Phenomenal Transparency and Cognitive Self-Reference," in Phenomenology and the Cognitive Sciences II (2003), 353-393. 
'special form of epistemic darkness': "Phenomenal transparency in general [...] means that something particular is not accessible to subjective experience, namely, the representational character of the contents of conscious experience." 22 This is the case, not only for sensory modalities and our integrated phenomenal model of the world, but also for much of our PSM, leaving us necessarily in a state of naïve realism with regard to appearings, including the appearing of the self.. ${ }^{23}$ Accordingly, the seeming of Chalmers' 'brute fact' becomes intelligible, since any conscious system with a phenomenally transparent self-model would, by necessity, be a naïve realist about itself. It makes sense to ask what an experience is like beyond the way it appears since the mode of presentation is phenomenally independent of how it appears to the phenomenal subject. That is to say, Metzinger's thesis is not a kind of self-deception - the self is a particular form of phenomenal content that is not epistemologically justified since it does not correspond to any single entity inside or outside of the self-representing system. ${ }^{24}$ As Metzinger puts it: "The phenomenal property of selfhood is constituted by transparent, nonepistemic self-representation." 25

In order to show that Metzinger is not tilting at straw men by assuming that the self is substantive or non-physical, he then needs to show how category errors that have been concretised through linguistic ascription can be revised. ${ }^{26}$ This is precisely the role of the PSM as Metzinger has formulated it. If a system integrates its own operations, using mental simulations of propositional structures that could be true or false, into its existing transparent self-model, while attributing the causal role of generating these representational states to itself, the system as a whole will consciously experience itself as the thinker and subject of its own thought, and, it will make this phenomenal content available for cognitive processing. ${ }^{27}$ That is, Metzinger does not simply refuse the ineliminability of de-se-attitudes, he characteristically introduces a third-term asymmetry in order to explain the existence of $I^{*}$-thoughts and $I^{*}$-sentences. ${ }^{28}$ The resulting explanation consists of showing how 'brute facts' regarding appearances as such, and I*-thoughts, can be accounted for by showing that they rely upon representational content that is in principle unavailable because, on the level of phenomenal experience, the first-person perspective is transparent, and, as such, is epistemically unjustified content.

22 Thomas Metzinger, Being No-One (Cambridge, MA: MIT Press, 2003), 169.

23 That is, where presentational states are subpersonal and subdoxastic, cf. Stephen Stich, "Beliefs and Subdoxastic States," in Pbilosophy of Science, 45 (December, 1978), 499-518.

24 Metzinger, Being No-One, 565.

25 Ibid., 337.

26 Cf. Patricia Churchland, "Can Neurobiology Teach Us Anything about Consciousness?," in Proceedings and Addresses of the American Pbilosophical Association, 67:4, (January, 1994) 23-40.

${ }^{27}$ Metzinger, "Phenomenal Transparency and Cognitive Self-Reference," 369.

$28 \mathrm{On} \mathrm{I}^{*}$ sentences and I* thoughts, cf. H. N. Castañeda, " $>\mathrm{He}<$ : A study on the logic of self-consciousness," in Ratio, 8 (1966), 130-157. 
Accordingly, using the resources that Metzinger has provided us with, we are able to account for the representation of the first-person perspective, since cognitive self-reference refers to the phenomenal content of a transparent self-model. That is, the conscious cognitive subject lacks epistemic justification for the corresponding belief states about that is actually being represented at the level of phenomenal content. ${ }^{29}$ Since I would argue that Metzinger is a reductive naturalist, rather than an eliminativist, I take him to have shown, following Patricia Churchland, that "The available theory specifies not only what counts as an explanation, but also the explananda themselves." 30 As a result, both the explanandum and explanans are open to revision, including a revision of experience itself.

\section{The Reality of Appearances}

I want to argue that Metzinger's account should be taken as a response to the attempt to refute reductive naturalism on the grounds of the principle of $\mathrm{AqA}^{31} \mathrm{I}$ am not arguing that reductive naturalism is correct, only that it can be defended against such arguments. Now, the phenomenologist and antireductivist may still argue that Metzinger engages in a performative contradiction, since it is consciousness that is supposed to be the condition of possibility for all knowledge. This is the argument of self-refutation, which, simplistically would look something like this:

The reductive naturalist:

i. Denies the existence of genuine subjects of experience.

ii. However, he himself is a genuine subject of experience.

iii. His statement that there are no genuine subjects of experience relies on him being a genuine subject of experience.

iv. Therefore, he is guilty of a performative contradiction by relying on that which he attempts to deny.

This is undoubtedly a simplification: nonetheless, it is precisely the second step of this argument that the principle of AqA is supposed to uphold. It is by adhering to this principle that the argument explicitly assumes something for which Metzinger provides an alternative explanation. By showing how the principle of appearing qua appearing is central to the refutation of reductive naturalism, I hope also to have shown how and why this is a transcendental argument. The refutation is question begging since it

\footnotetext{
${ }^{29}$ Metzinger, Being No-One, 404.

30 Patricia Churchland, "The Hornswoggle Problem," in The Journal of Consciousness Studies, 3:5-6, (1996), 398.

31 Though Chalmer's 'call to arms' is directed towards Dennett, it clearly applies to Metzinger: "Dennett [...] has often stated how radical and counterintuitive his position is. So it is clear that the default assumption is that there is a further problem of explanation; to establish otherwise requires significant and substantial argument." Chalmers, "Moving Forward on the Problem of Consciousness," 9
} 
assumes AqA to be true, while it is precisely AqA that reductive naturalism would both dispute and revise. What's more, by providing an explanation for the 'seeming' of this 'genuine' subject of experience, we can contend that the argument against reductive naturalism relies upon a naturalistic fallacy, viz., that the reality of consciousness is given in experience. Thus, we can also show that the argument that reductive naturalism is self-refuting is question begging, since it rests upon an explanatory principle, which has been illegitimately construed as transcendental.

Let us briefly consider another example of the refutation argument, this time found in Chalmers and Goff:

i. There is something that 'it is like' to be a subject of experience. $^{32}$

ii. We have direct knowledge of subjective experiences from first-person access.

iii. Subjective experiences are the central data that we want from a science of consciousness.

iv. No third person data will express this data.

C. First-person data are irreducible to third person data.

In this form, the principle of appearing qua appearing is outlined in the second and third premises. Note that while it does not presuppose incorrigibility as such, the first person is assumed to enjoy intimacy with its own conscious states, so that there could be no more reality to conscious experiences than we are able to discover through our phenomenal experience of them..$^{33}$ This is just another way of saying that: "In the special case of conscious experience, appearance and reality cannot come apart [...] How things appear to us just is the reality we are attending to when we attend to our conscious experience." 34 But where is the evidence for the sufficiency of appearances? The terms upon which we are allowed access to this realm of appearances as such is exactly what is presupposed: First-person phenomenology. And how could we deny that we always begin from the firstperson perspective?

Following Metzinger, the reductive naturalist can argue that:

i. Consciousness, the phenomenal self, and the first-person perspective are representational phenomena.

ii. The first-person approach was historically but is not nomologically fundamental.

iii. We naively operate from a first-person perspective.

32 On the use of the phrase 'what it is like,' cf. William Lycan, Consciousness and Experience (Cambridge, MA: MIT Press, 1996), 77.

33 The epistemic consequences of this move are briefly dealt with below.

${ }^{34}$ Goff, op cit. 
iv. A conscious system seems to be a subject of experience when it generates experiences that include the experiences of being a subject in the world.

C. Persons, selves, and subjects of $\mathrm{I}^{*}$-thoughts are unjustified appearances.

Take Chalmers' statement: 'Experience is the most central and manifest aspect of our mental lives, and indeed is perhaps the key explanandum in the science of the mind. Because of this status as an explanandum, experience cannot be discarded like the vital spirit when a new theory comes along. ${ }^{35}$ As we have shown, this argument contains a transcendental component in the form of AqA. By taking experience as fundamental, there is a sense in which the anti-reductionist remains unable to give an account of why there is experience in the first place. ${ }^{36}$ The reductive naturalist on the other hand hopes to explain why consciousness and first person experience is experienced as a brute fact, denying the principle of $\mathrm{AqA}$ and providing an explanation for those causes and reasons of appearances that do not appear within 'appearings.' That is, the reductive naturalist can grant Chalmers' distinction between the phenomenal and psychological aspects of mind - 'thinking that $q$ ' is not the same as 'sensing $q$ ' - without conceding the claim that sensing is direct and unmediated. ${ }^{37}$ Countering the principle of AqA, Metzinger shows that the positing of appearances as such is an impoverishment of explanation, since there is a sub-linguistic reality that is inaccessible to first person description: the reality of consciousness is for the most part independent of the subject of consciousness. ${ }^{38}$

\section{A Weaker Form of Transcendentalism}

There is a relevant though weaker argument that we have not yet dealt with, which suggests that even the reductive naturalist is a weak transcendentalist regarding appearances.

The weak transcendentalist suggests:

${ }^{35}$ Chalmers, "Facing up to the Problem of Consciousness," 206.

${ }^{36}$ Cf. Ibid., 210.

37 This is in accord with Wilfrid Sellars' claim: "The fact that something looks red to me can itself be experienced. But it is not itself an experiencing." Wilfrid Sellars, "Empiricism and the Philosophy of Mind," in Wilhelm deVries and Timothy Triplett eds., Knowledge, Mind, and the Given: Reading Wilfred Sellars's 'Empiricism and the Philosophy of Mind' (Cambridge: Hackett, 2000), V.

38 Of course, the attempt to distinguish between 'thinking that $q$ ' and 'sensing $q$ ' is a difficult issue in itself, and a subject that requires further elucidation, though Metzinger's account in Thomas Metzinger, Being No-One makes a serious attempt at disentangling the associated problems. Moreover, such a distinction could be adequately parsed, it would still be incumbent upon the argument against reductivism to produce a mechanism by which 'sensing $q$ ' ought to be taken to be unmediated. Thanks to an anonymous review for raising this point. 
i. Reductive naturalism does not eliminate conscious appearances.

ii. Furthermore, reductive naturalism necessitates the existence of those appearances as a target phenomenon of explanation and reduction.

C. Conscious appearances are a transcendental condition for the possibility of reductive naturalism.

This is admittedly a very thin version of transcendentalism that only advocates that conscious appearances are necessary in order to formulate an account thereof..$^{39}$ Nevertheless, if we look more carefully at this assertion, it should help to clarify more specifically the terms upon which reductive naturalism overcomes the principle of AqA. First, let us state upfront that this argument does nothing to undermine what we have said above, since the antireductionist and phenomenologist whose claims we outlined clearly add more properties to this weaker form of transcendentalism, primarily in the form of first-person phenomenology. Nevertheless, in the spirit of attempting to answer such a call to arms, it is incumbent upon the reductive naturalist not to simply obviate this issue by eliminating it. Should the reductive naturalist then accept weak transcendentalism, or can she show why this strategy is also question begging?

The problem of weak transcendentalism is pithily described by F. H. Bradley's claim:

[F]or nothing is actually removed from existence by being labeled 'appearance.' What appears is there, and must be dealt with; but materialism has no rational way of dealing with appearance. ${ }^{40}$

At first glance, the weak transcendentalist is surely correct, and since Metzinger argues that conscious appearances should not be granted ontological status, he is guilty of not answering consciousness on its own terms. ${ }^{41}$ Nevertheless, we ought to ask exactly what appearances do for weak transcendentalism. As noted above, Chalmers allows two options when it comes to appearances: either sign up to the principle of AqA, or eliminate

39 This argument is largely due to Dan Hutto, in conversation.

${ }^{40}$ Francis Bradley, Appearance and Reality, (Oxford: Oxford University Press, 1930), 12. Dan Hutto reiterates the point: "Experience cannot simply be explained away. If one admits that experiences appear to exist $[\ldots]$ then they must be accounted for. We are owed an explanation of what accounts for the fact that experiences appear to be as they are. Specifically, we must account for their apparent qualitative aspects. Thus [...] to say that experiences are mere appearances hence not real does not reduce the materialist's explanatory burden." Dan Hutto, "Author's Précís of Beyond Physicalism," in SWIF Philosophy of Mind Review, (2000), 5.

${ }^{41}$ Dan Hutto makes this point in relation to Dennett. Dan Hutto, "An Ideal Solution to the Problems of Consciousness," in The Journal of Consciousness Studies, 5:3, (1998), 330. 
phenomenal consciousness altogether. ${ }^{42}$ The reductive naturalist account outlined above provides an alternative to this dichotomy in order to explain appearances - the further question is whether or not explanation entails weak transcendentalism as Bradley put it. I want to suggest that that this is not the case because of two possible unstated inferences in the weak transcendentalist position.

For the weak transcendentalist position to work, its exponent needs to infer either a) appearances block revision, or b) conscious appearances are a special case. Both adhere to the principle of AqA. Why? b) necessitates a limited foundationalism in the phenomenal domain, as Dan Hutto argues:

$[1 \mathrm{t}$ is not possible to regard experiences as properties of objects. This is primarily due to the fact that modes of presentation logically imply a subject to whom they are presented. ${ }^{43}$

This objection has been dealt with above where I suggest it begs the question when used to refute reductive naturalism. a) it attempts to block the revision of appearances: a claim which, although it seems to be innocuous, prompts the question - why would we save appearances rather than revise them? The key point here is epistemic: for the reductive naturalist, appearances themselves cannot count as knowledge and are open to revision. On our account, the reductive naturalist attempts to explain appearances, rather than 'explain them away.'

If we go back to the principle of AqA, the point is simply that transcendentalism about appearances asserts that appearances should be taken on their own terms; appearing qua appearing as such, rather than as something else. Reductive naturalism can accept that conscious 'appearings' are only appearance, but this is also to say that there are no intrinsic epistemic relations of intentional content for conscious states. It looks like the weak transcendentalist is attempting to smuggle in a kind of non-inferential justification here, which is exactly what Hutto suggests, arguing that experiences are "fundamentally grounded in our non-conceptual way of being in the world," so that "our talk of how things appear to us is not open to challenge precisely because it serves as non-inferential justification for other judgments and beliefs." ${ }^{44}$ Experiences become the very ground of justification, since they are inextricable from our primary engagement with things.

Do experiences provide a non-inferential ground of justification? Or, on the other hand, can we preserve the idea that experiences might be sub-

42 E.g.: "The main intuition at work is that there is something to be explained - some phenomenon associated with first person experience [...] The only consistent way to get around the intuitions is to deny the problem and the phenomenon altogether." Chalmers The Conscious Mind, 110.

43 Dan Hutto, Beyond Physicalism, (Amsterdam/Philadelphia: John Benjamins, 2000), 99.

${ }^{4}$ Dan Hutto, "Turning Hard Problems on Their Heads," in Phenomenology and the Cognitive Sciences, 5:1, (March 2006), 2; 10. 
conceptual doxastic content, whilst also saying that they are open to revision and challenge? There is not the space to outline a full response to this problem: nonetheless, we need only to show that the reductive naturalist will provide an alternative response in order to highlight the question-begging nature of the argument. Metzinger quite clearly asserts the epistemologically unjustified nature of experiences, refusing the claim that they provide a ground for justification since they are both physically reducible and in principle revisable. Epistemologically, there needs to be a 'justification-maker' that does not derive from other propositional content in order for the weak transcendentalist argument to follow, a condition that makes it epistemologically appropriate for content justification. ${ }^{45}$

The anti-reductionist seems to be capitulating to the 'myth of the epistemic given' in its most rudimentary form. In Empiricism and the Philosophy of Mind, Wilfrid Sellars makes a case against the epistemic given: knowledge of the given that can be said to be autonomous or independent of other matters of fact. ${ }^{46}$ Sellars is concerned with the possibility of accounting for the existence of experiences without taking them on their own terms: his account of the myth of the epistemic given is not an attempt to eliminate 'appearings' as such, rather it is simply an attempt to relieve them of their status as providing an epistemological bedrock for justified belief. On Sellars' account, the given cannot be said to provide non-inferential knowledge or epistemic justification, since it does not have the necessary means to be an 'efficacious evidenceprovider.'

The problem for the epistemic given would not disappear even if we were to accept AqA in order to talk about 'appearings themselves' without reference to the world. This is because, according to deVries and Triplett, the doctrine of the given requires only "that for any empirical knowledge that $p$, some epistemically independent knowledge $g$ is epistemically efficacious with respect to $p . "{ }^{\prime \prime} 7$ Indeed, the principle of AqA obscures the role the given plays since it attempts to allow 'appearings' to be treated as independent of other cognitive and physical structures. So, even if we accept the distinction between

45 Cf. Jim Pryor, "Is There Non-Inferential Justification?," in E. Sosa and M. Steup eds., Contemporary Debates in Epistemology (London: Blackwell, 2004).

${ }^{46}$ Cf. Sellars, "Empiricism and the Philosophy of Mind," VIII.32; also James O’Shea, Wilfred Sellars (Cambridge: Polity Press, 2007), 106ff.

${ }^{47}$ Wilhem de Vries and Timothy Triplett eds., Knowledge, Mind, and the Given: Reading Wilfred Sellars's 'Empiricism and the Philosophy of Mind' (Cambridge: Hackett, 2000), 104-5. Chalmers argues that he is able to circumnavigate the myth of the given, but, whilst his phenomenal epistemology certainly deserves greater attention, it is enough to show that his method introduce a new kind of justifying relation 'constitution' - looks like it succumb to the myth in three ways: a) Chalmers reasoning for the existence of the 'constitution' relation is circular - he argues that we should accept it because of the role that it plays in our epistemic activity; b) 'constitution' is structured in much the same way as acquaintance - Sellars' primary target in EPM; c) its role is defined in terms of the provision of incorrigible epistemic efficacy: 'It is the role an experience plays in constituting a direct phenomenal belief that makes that belief incorrigible, and indeed incorrigible in virtue of its phenomenological structure, and so justified.' David Chalmers, "Mind and Modality," in Lectures given at Princeton University (October 12-16 1998). 
the psychological and the phenomenal for conscious 'appearings,' there is a further question to ask: how do we get from this 'appearing' to knowledge regarding that 'appearing. ${ }^{4} 8$ Put another way: what else would need to be in place before such 'appearings' could serve to justify knowledge? Sellars' point can be made very simply: an experience or 'appearing' does not justify some belief or other by merely 'appearing,' and so the case for an epistemological AqA should not be granted.

The weak transcendentalist position relies upon a 'justification-maker' that is independent from other propositional content. That is to say, 'appearings' are supposed to be in some way epistemically independent of and prior to further epistemic activity. There are two horns for this attempt to conceive of the role of 'appearing' as 'epistemologically efficacious.' On the first horn, 'appearing' is supposed to be non-propositional, in which case it will be epistemologically inefficacious since it is not an epistemologically appropriate condition for content justification - it cannot provide an independent reason or premise to conform or disconfirm beliefs. On the second horn, 'appearing' might be conceived propositionally, in which case it will not turn out to be epistemologically independent in the way the weak transcendentalist desires, and it is therefore revisable in the same way as other empirical knowledge. ${ }^{49}$ On both horns, the epistemic version of AqA attempts to provide conscious 'appearings' with the capacity to justify cognitive states without needing justification. Laurence BonJour summates the problem with this approach:

$\Pi \mathrm{t}$ is clear on reflection that it is one and the same feature of a cognitive state, namely, its assertive or at least representational content, which both enables it to confer justification on other states and also creates the need for it to be itself justified - thus making it impossible in principle to separate these two aspects. ${ }^{50}$

Nevertheless, the weak transcendentalist might argue that in denying her position, the reductive naturalist inevitably 'muddies the waters' of the explanandum with various explanans by importing description into the target phenomenon. Josh Weisberg makes this point against Metzinger; " $\mathrm{I}] \mathrm{f}$ a theory cannot explain why the explanandum appears as it does to common sense - that

48 Ruth Millikan also makes this point, cf. Ruth Millikan, "How We Make Our Ideas Clear: Epistemology for Empirical Concepts," in On Clear and Confused Ideas (Cambridge: Cambridge University Press, 2000), 95-108. Gallagher and Zahavi make this mistake in relation to philosophical phenomenology, suggesting that phenomenology does not succumb to the myth since it phenomenology is concerned with experiences rather than the relation of experiences to the world, cf. Shaun Gallagher \& Dan Zahavi, The Phenomenological Mind: An Introduction to Philosophy of Mind and Cognitive Science, 24.

${ }^{49}$ Cf. O'Shea, op cit., 111-112; p. 209n10; deVries and Tripplett eds., Knowledge, Mind, and the Given: Reading Wilfred Sellars's 'Empiricism and the Philosophy of Mind,'105-6.

${ }^{50}$ Laurence BonJour, The Structure of Empirical Knowledge (Cambridge, MA: Harvard University Press, 1985), 78. 
is if it cannot 'save the common-sense appearances' - we do not count it as a successful theory." ${ }^{51}$ However, the reductive naturalist as she has been defined here expects that the very practice of scientific and philosophical progress will enrich and revise the explanandum itself: conscious appearance itself will alter as theory proceeds. Moreover, claims to the opposite - that "common-sense appearances" are somehow pristine phenomena that are simply given - are open to the charge of adopting a form of idealism toward consciousness.

Consequently, reductive naturalism does not fall foul of Bradley's censure, removing something from existence by labeling it as appearance, since the explanation of the origin of those 'common-sense appearances' and corresponding theoretical intuitions may well completely revise and destroy them. ${ }^{52}$ The weak transcendentalist relies upon an austere version of the appearance / reality distinction which the reductive naturalist can jettison. Hutto's argument, which claims that 'to say that experiences are mere appearances hence not real does not reduce the materialist's explanatory burden,' presumes that reductive naturalism will attempt to axiomatically eliminate rather than explain and revise appearances. On the other hand, the reductive naturalist can agree with Sellars that:

[E]mpirical knowledge, like its sophisticated extension, science, is rational, not because it has a foundation but because it is a self-correcting enterprise which can put any claim in jeopardy, though not all at once. ${ }^{53}$

From this we may conclude that the weak transcendentalist argument is also predicated upon $\mathrm{AqA}$, and hence question begging, since the appearances it would save could not provide a neutral ground for the explanandum. Moreover, weak transcendentalism requires an epistemic argument for the unjustified inference to either the irrevisability or the special status of conscious appearances. That is to say, only if the explanandum is supposed to be transcendentally autonomous from the explanans does weak transcendentalism follow. Outlining this third response clears up some of the issues regarding the principle of AqA, with the implication that the antireductionist may well be forced to capitulate to some form of the given.

51 Josh Weisberg, "Consciousness Constrained: A Commentary on Being No One," in Psyche, 11:5, (2005), 6.

52 Metzinger makes this point; Thomas Metzinger, "Reply to Weisberg," in Psyche, 12:4, (2006), 3. This is consistent with the account of reduction proposed by Churchland; "Reduction is not a strict logical deduction of the terms of one theory to those of another, but rather that the 'image of the higher order theory,' or specifically, its explanatory and predictive resources, will be preserved in lower level theory." Paul Churchland, Matter and Consciousness, 2nd Edition (Cambridge, Mass.: MIT Press, 1989), 49. This is in distinction to the deductive-nomological approach, e.g. Earnest Nagel, The Structure of Science (Cambridge: Hackett, 1961), 336-397.

${ }^{53}$ Sellars, "Empiricism and the Philosophy of Mind," VIII. 


\section{Conclusion}

I hope to have shown that attempts to refute reductive naturalism by invoking AqA surreptiously ascribe a transcendental status to conscious appearances, and that this strategy is question begging since it imputes to the reductive naturalist concepts which are encumbered with the very assumptions which she would deny and revise. There may well be other reasons why we would want to hold a non-reductive or phenomenological position, but whatever those reasons might be, they should not be set out on the basis of such claims. As Rinofner-Kreidl and Lynne Rudder Baker have pointed out, Metzinger's work has serious consequences for our semantic and epistemic understanding of reality. In this regard, Dan Zahavi suggests: "Why not rather insist that the self is real if it has experiential reality and that the validity of our account of the self is to be measured by its ability to be faithful to experience?." 54 However, this would effectively go full circle, arguing that the contents of our ontology should be determined by that which was presupposed in the first place: appearing qua appearing. Rudder-Baker makes this allegiance clear: "My experience of being a conscious subject is evidence that I am a subject, and this evidence overwhelms any possible evidence that I may have for any scientific theory to the contrary." ${ }^{5}$ My aim in this paper has been to show how anti-reductive philosophers at least implicitly rely upon a transcendental assumption that precludes explanation by widening the gap between conceptual speculation and empirical study. Nevertheless, I would suggest that, instead of erecting transcendental schemas that seem designed to resist explanatory integration, both the explananda and the explanans of conscious experience ought to be left open to revision. ${ }^{56}$

Department of Contextual Studies, University for the Creative Arts, United Kingdom

\section{References}

Block, N., "Begging the Question against Phenomenal Consciousness," in Behaviour and Brain Sciences, 15:2 (1992).

Block, N., "On a Confusion About a Concept of Consciousness," in Behaviour and Brain Sciences, 18: 2 (1995).

BonJour, L,. The Structure of Empirical Knowledge (Cambridge, MA: Harvard University Press, 1985).

Bradley, F.H., Appearance and Reality (Oxford: Oxford University Press, 1930).

${ }^{54}$ Dan Zahavi, Subjectivity and Selfhood: Investigating the First Person Perspective (Cambridge, MA: The MIT Press, 2005), 128.

55 Lynne Rudder-Baker, "Naturalism and the First-Person Perspective," in Georg Gasser ed., How Successful is Naturalism? (Publications of the Austrian Ludwig Wittgenstein Society: Ontos Verlag, 2007), 24.

56 Thanks to Ray Brassier, Dan Hutto, Alex Tillas and an anonymous reviewer for comments on earlier versions of this paper. 
Carruthers, G. \& Schier, E., "Our Intuitions about Consciousness are Inconsistent," Paper presented at the Australasian Association for Philosophy Conference, Melbourne, Australia (July 2008).

Castañeda, H.N., " $>\mathrm{He}<$ : A study on the logic of self-consciousness," in Ratio, 8 (1966), 130-157.

Chalmers, D., "Consciousness and Cognition," <http://consc.net/papers/cand-c.html>, (1990).

"Facing up to the Problem of Consciousness," in The Journal of Consciousness Studies, 2:3 (1995).

The Conscious Mind (Cambridge, MA: MIT Press, 1996).

"Reply to Mulhauser's Review of "The Conscious Mind," in Psyche, 2:35 (November 1996).

, "Moving Forward on the Problem of Consciousness," in The Journal of Consciousness Studies, 4:1. (1997).

"Mind and Modality," in Lectures given at Princeton University (October 12-16 1998).

Churchland, P., "Eliminative Materialism and the Propositional Attitudes," in The Journal of Philosophy, vol. 78:2, (1981), 76-90.

Matter and Consciousness, 2nd Edition (Cambridge, Mass.: MIT Press, 1989). "Can Neurobiology Teach Us Anything about Consciousness?," in Proceedings and Addresses of the American Philosophical Association, 67:4 (January, 1994) 23-40.

"The Hornswoggle Problem," in The Journal of Consciousness Studies, 3:5-6 (1996).

Dennett, D., Consciousness Explained (Boston: Little Brown, 1991).

Gallagher,S. \& Zahavi, D., The Phenomenological Mind: An Introduction to Pbilosophy of Mind and Cognitive Science (New York: Routledge, 2008).

Goff, P., "Appearance, Reality, and the Reality of Appearance," Paper given at Brains Persons and Society, Milan (2006).

Güzeldere, G. and Aydede, M., "On the Relation Between Phenomenal and Representational Properties," in Behavioural and Brain Sciences, 20:1 (1997).

Husserl, E., "Philosophy as a Rigorous Science," Q. Lauer (trans.), in P. McCormick and F. Elliston (eds.) Husserl: Shorter Works (Notre Dame: University of Notre Dame Press, 1911/1981).

Ideas pertaining to a Pure Phenomenology and to a Phenomenological Philosophy, First Book, trans. by F. Kersten (Dordrecht: Kluwer Academic Publishers, 1982).

Logical Investigations I (London: Routledge, 2001).

Hutto, D., "An Ideal Solution to the Problems of Consciousness," in The Journal of Consciousness Studies, 5:3 (1998).

"Author's Précís of Beyond Physicalism," in SWIF Pbilosophy of Mind Review (2000). 2000).

Beyond Physicalism (Amsterdam/Philadelphia: John Benjamins, 
"Turning Hard Problems on Their Heads," in Phenomenology and the Cognitive Sciences, 5:1 (March 2006).

Levine, J., "Out of the closet: A qualophile confronts qualophobia," in Philosophical Topics, 22 (1994), 107-26.

Lycan, W., Consciousness and Experience (Cambridge, MA: MIT Press, 1996).

Metzinger, T., "Phenomenal Transparency and Cognitive Self-Reference," in Phenomenology and the Cognitive Sciences II, (2003), 353-393.

Metzinger, T., Being No-One (Cambridge, MA: MIT Press, 2003). "Reply to Weisberg," in Psyche, 12:4 (2006).

Millikan, R., "How We Make Our Ideas Clear: Epistemology for Empirical Concepts," in On Clear and Confused Ideas (Cambridge: Cambridge University Press, 2000).

Nagel, E., The Structure of Science (Cambridge: Hackett, 1961).

Nagel, T., "Conceiving the Impossible and the Mind-Body Problem," in Philosophy, 73: 285 (1998).

O’Shea, J., Wilfred Sellars (Cambridge: Polity Press, 2007).

Patocka, J., An Introduction to Husserl's Phenomenology, trans. by Erazim Kohak (Chicago, IL: Open Court, 1996).

Plato and Europe, trans. by Petr Lom (Stanford: Stanford University Press, 2002).

Pryor, J., "Is There Non-Inferential Justification?," in E. Sosa and M. Steup eds., Contemporary Debates in Epistemology (London: Blackwell, 2004).

Rinofner-Kreidl, S., "The Limits of Representationalism," in The Journal of Consciousness Studies, 11:10-11 (October-November, 2004).

Rockwell, T., "The Hard Problem is Dead, Long Live the Hard Problem," <http:/ /www.cognitivequestions.org/hardproblem.html>, (1999).

Rudder-Baker, L., Saving Belief: A Critique of Physicalism (Princeton, NJ: Princeton University Press, 1987).

Searle, J., The Rediscovery of the Mind (Cambridge, Mass: MIT Press, 1992).

Sellars, W., "Empiricism and the Philosophy of Mind," in Wilhelm deVries and Timothy Triplett eds., Knowledge, Mind, and the Given: Reading Wilfred Sellars's 'Empiricism and the Philosophy of Mind' (Cambridge: Hackett, 2000).

Strawson, G. "Realistic Monism," in Alan Freeman ed., Consciousness and it's Place in Nature: Does Physicalism Entail Panpsychism? (Exeter: Imprint, 2006).

Stich, S., "Beliefs and Subdoxastic States," in Philosophy of Science, 45 (December, 1978), 499-518.

Trafford, J., "Modal Rationalism and the Transference of Meaning," in Croatian Journal of Philosophy, 10:2 (2010), 97-107.

de Vries, W. \& Triplett, T. eds., Knowledge, Mind, and the Given: Reading Wilfred Sellars's 'Empiricism and the Philosophy of Mind' (Cambridge: Hackett, 2000).

Weisberg, J., "Consciousness Constrained: A Commentary on Being No One," in Psyche, 11:5 (2005). 


\section{THINGS ARE NOT WHAT THEY SEEM}

Zahavi, D., Subjectivity and Selfhood: Investigating the First Person Perspective (Cambridge, MA: The MIT Press, 2005). 